\title{
Editorial: Geoscience in a time of pandemics
}

\author{
Jonathan P. Tennant ${ }^{1, *}$, Sam Illingworth ${ }^{2, * *}$, Iain Stewart ${ }^{3, *}$, and Kirsten von Elverfeldt ${ }^{4, *}$ \\ ${ }^{1}$ Institute for Globally Distributed Open Research and Education, Gianyar, Bali, Indonesia \\ ${ }^{2}$ Department of Natural Sciences, Manchester Metropolitan University, Manchester, UK \\ ${ }^{3}$ School of Geography, Earth and Environmental Sciences, University of Plymouth, Plymouth, UK \\ ${ }^{4}$ Department of Geography and Regional Studies, Alpen-Adria-Universität Klagenfurt, Klagenfurt, Austria \\ *Executive editors \\ ${ }^{* *}$ Chief-executive editor
}

Correspondence: Sam Illingworth (s.illingworth@mmu.ac.uk)

Published: 20 March 2020

We, the executive editors at Geoscience Communication, sincerely hope that this message finds you and your loved ones in good health. We are in the midst of a global-health crisis, the coronavirus pandemic (COVID-19). This affects all of us, and we truly hope that you are remaining safe and taking all necessary precautions. We all are facing difficult times ahead, and we hope that we can all together find the strength and courage within to do our best.

During this time, it is critical that we all stay as informed as possible about updates, including the latest scientific research. For all of you, we hope that you commit to only sharing verified, reliable information to help cancel out a lot of the noise being shared around. For example, John Hopkins University has a Coronavirus Resource Center (https: //coronavirus.jhu.edu/map.html) with a lot of valuable information that is updated constantly.

While the pandemic is primarily a global-health and medical issue, it affects and is affected by all aspects of life. Economics, politics, climate research, and psychological sciences all have a role to play here. Even geoscience as a research discipline is relevant. For example, we know that virus transmission is strongly controlled by geospatial connections between infected hosts and other non-infected individuals, as well as climatic factors, which can help to understand and mitigate transmission. Making sure that we have enough clean and drinkable water in the future will require input from the hydrogeology and geochemistry communities in monitoring the metals and minerals in aquifers. There is a clear role for the space, Earth weather and climate, and stratospheric monitoring research communities in the present pandemic. All of these things remind us that life, in its various forms, is intimately connected to the Earth.

Therefore, we strongly encourage geoscientists working on these topics to continue to engage with the public, policymakers, and all other stakeholder groups in helping to combat this evolving threat to global health - and to make this research freely available and easily accessible to all.

Finally, as geoscience communicators, now is a time when we might feel that we have a responsibility to convey something meaningful about the science behind the pandemic to anxious publics. However, we should be guided in this task by the empirical evidence around crisis communications. In that regard, the 2012 paper in Risk Analysis by Michelle Wood and colleagues on "Communicating actionable risk for terrorism and other hazards" offers three headline messages for us to bear in mind as we contemplate communicating in these noisy and fearful times (Wood et al., 2012):

1. The strongest motivator of taking preparedness actions is when average people, not experts, share what they have done to prepare with other individuals who have not done much.

2. Communications to increase public preparedness should emphasize the actions people should take to become better prepared rather than the physical impacts of disasters, the science behind those impacts, and the magnitude of negative consequences that may ensue.

3. Information is only deemed important when it is consistent over many different public communication channels, over time, and for the long haul. Some fear that the public will "tune out" repetitive messages, but research 
suggests the opposite; repetition is essentially the only way to help people "tune in".

An emergency crisis is not the time to get carried away with science lessons. Keep it simple; share ordinary stories of preparedness and resilience; and try to consistently and repeatedly relay the key messages of the health and emergency services. At the same time, an emergency crisis is the time to show empathy and humility whilst demonstrating the public value of geoscience and taking responsibility for our research. We are all in this together.

Jon, Sam, Iain, and Kirsten.

\section{References}

Wood, M. M., Mileti, D. S., Kano, M., Kelley, M. M., Regan, R., and Bourque, L. B.: Communicating actionable risk for terrorism and other hazards, Risk Analysis: An International Journal, 32, 601-615, 2012. 